\title{
Study of Water \& Air Environment for Impact Analysis of Proposed Bhaurant Dam using Interaction Matrices Approach
}

\author{
Mr. Zishan Aslam \\ (Prof. Department of Civil EnggBGSB UniversityRajouri,J\&K)
}

\begin{abstract}
This study presents the findings of Environmental Impact Assessment (EIA) for the proposedBhaurat Dam Project. In this study data pertaining to water and air environment within the study area $10 \mathrm{kms}$ of radius from the dam site has been investigated in the upstream and downstream side of the proposed dam site. On the basis of impact analysis adopting using Matrice and Interaction Matrix approaches and results of the base-line data, it has been found that dam construction activity is more dominant over other aspects. Considered for correlation these aspects are effect on Regional Ecology and Environment, Irrigation Benefits, Forest Loss, Regional Economy, Social Aspects, Geology, Hydrology, Moreover, results indicate that there would be minimal adverse impact on regional ecology and environment following the construction of dam. Instead, it may offer benefit to this region. It may enhance irrigation activity leading to agricultural productivity, increase vegetation and green areas in this semi-arid region of the state.
\end{abstract}

\section{Introduction}

This study was conducted on proposed Bhaunrat Dam in District Lalitpur UP. The Bhaunrat Dam is proposed to be constructed across Jamini River in District Lalitpur, UP. The dam will submerge 1230 hectares of land with an objective to provide estimated culturable command area of about 11699 hectares. The main purpose of the $19.93 \mathrm{~m}$ high, with 10 spillways having dam line of $4.2 \mathrm{kms}$ long of Bhaunrat Dam is irrigation.

Man's impact on his environment and his efforts to prevent or mitigate the impact has a long history. There has been a long tradition of land- use planning concerned with the prevention or reduction of detrimental impacts by means of planning permits or denial of such permits In the present modern world, the impact (positive/or negative) is assessed through knowledge and scientific means. The Environmental Impact Assessment (EIA) has become an important tool to gauge the likely impacts of any development projects. Water resources projects like Dam construction has also been considered as a very important activity from environment, economic and social development point of views. The construction new Dam is very critical because of the associated project impact on the environment. The damming of a river will have dramatic consequences on the nature of the environmental both upstream and downstream of the dam and its flow regime. The reservoir water spill out into the surrounding environmental resulting into flooding the natural habitat that existed before the dam's construction. Also, a dam acts a barrier between the upstream and downstream habitat of migratory river animals thus threatening to decrease their reproduction numbers and reduce the species population. The water temperature will also have some effect.

\subsection{Construction of Dams for Irrigation Purpose}

Water is the vital resource to support all forms life on earth. Unfortunately, it is not evenly distributed over the world by season or location. Some parts of the world are prone to drought making water a scarce and precious commodity, while in other parts of the world it appears in raging torrents causing floods and loss of life and property. Throughout the history of the world, dams and reservoirs have been used successfully in collecting, storing and managing water needed to sustain civilization.

Even today, water remains essential for the survival of mankind and the future development of the world's cities, industries and agriculture. Today there is a significant demand on the world's water. As the world population continues to grow at the rate of over 100 million people each year, so does the demand for water. At the same time, there is a careless use of our natural resources and accelerated pollution of the environment. The fact that a significant portion of the available water in the world is too contaminated for domestic use makes this situation very critical.

One of the most efficient ways to manage water resources for human needs is by the construction of dams that create reservoirs for the storage and future distribution. Currently there are about 45,000 dams higher than 15 meters throughout the world. While some are more than 2,000 years old, about $73 \%$ have been built in the last 50 years. The reservoirs formed by these dams store some 3,600 km3 of usable water. The primary benefit of dams and reservoirs in the world is water supply. Other key purposes and benefits include:

- Irrigation for agriculture (food supply)

- Flood control 
- Hydropower

- Inland navigation

- Recreation

\subsection{Location of project}

The proposed dam project where this study has been conducted is located in District Lalitpur. Lalitpur district falls in the Bundelkhand region forming the southern fringe of Uttar Pradesh demarcated by the Vindhyan hills and plateau. It falls under semi-arid climatic zone characterized by rugged undulating terrain, and low soil cover with granitic outcrops. The area with poor soil cover and uncertain rainfall has limited agricultural development for about 5.71 per cent of the total $240,928 \mathrm{~km}^{2}$ geographic area. Lalitpur district has 11.07 per cent forest cover within its $5039 \mathrm{~km}^{2}$ of geographic area.

\subsection{Geography and Topography:}

District Lalitpur is ravenous, undulating and hillocks bounded by Vindhyan Plateau in south, river Yamuna in north, river Ken in east and rivers Betwa and Pahuj in west. While the Yamuna flows from west to east, its first order tributaries viz., Betwa, Ken, Pahuj, Baghain, and Paisuni flow from south to north. Second order tributaries of the Yamuna are Dhasan, Jamini, Birma, Sonar, Katne, Bewas, and Kopra.

The entire system of drainage and stream flows forms a part of Ganga basin. The region generally slopes from south to north. The elevations in the area ranges from $600 \mathrm{~m}$ above mean sea level (MSL) in southern part to $150 \mathrm{~m}$ MSL near Yamuna River.

\subsection{Ground Water Resources}

Water aquifer is inadequate and non-dependable largely due to hard rock hydro-geological conditions. Except a belt along the Yamuna river and a few rivers and few pockets here and there already having tube-well, water yield in the remaining part is very low.

\subsection{Rainfall Pattern}

Rainfall is the ultimate source of surface, ground, green and blue water resources for raising biomass and other utilities. The average annual rainfall of Bundelkhand in Uttar Pradesh is $876.1 \mathrm{~mm}$ with a range of 786.6 to $945.5 \mathrm{~mm}$. About $90 \%$ of the rainfall is received in the monsoon season of July to September in about 30-35 events or spells.

Rainfall variation within the season is important for crop production and rain in September is crucial for the maturity of Kharif crops and sowing of Rabi crops. Delayed on set of rains, early withdrawal or long dry spells in between also lead to drought like situation. The U.P. part of the region experienced rainfall deficit of $25 \%$ in $2004-05,33 \%$ in the year $2005-06$ which went up to $45 \%$ in $2006-07$ and $56 \%$ in $2007-08$. Five out of seven districts had more than 50\% rainfall deficit. All the districts experienced meteorological drought.

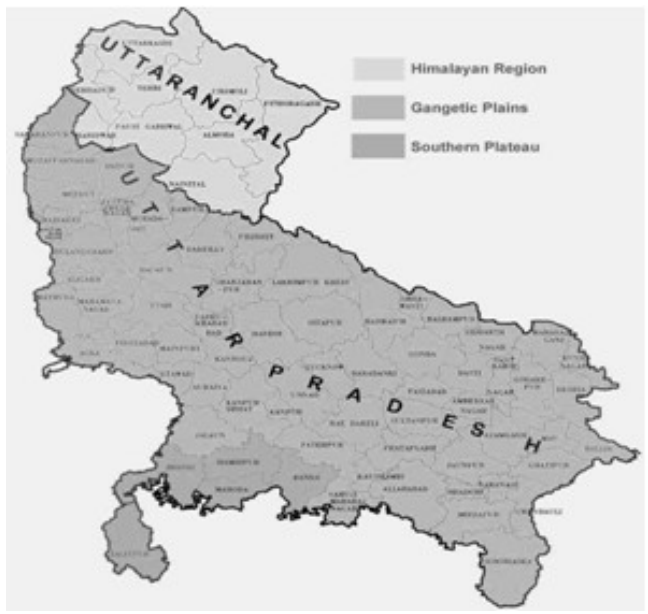




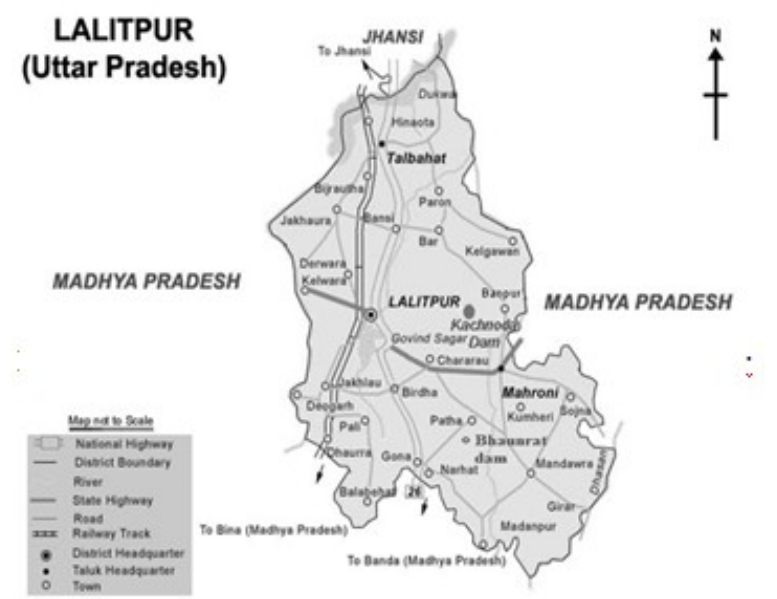

Fig 1.1: Maps of Uttar Pradesh Showing District Lalitpur

\section{Dam project detail}

The proposed Bhaunrat Dam Project envisages construction of a $4.20 \mathrm{~km}$ long and $19.93 \mathrm{~m}$ high above river bed with a gross storage of $50.44 \mathrm{mcm}$ across Jamini river (a tributary of river Betwa), about 20 $\mathrm{km}$ downstream of existing Jamini dam near village Bhaira in Mehrauni Tehsil of District Lalitpur of Uttar Pradesh. A gated spillway of $157 \mathrm{~m}$ length is proposed to be constructed to pass the maximum flood discharge of 5000 cumecs. It is envisaged to irrigate an area of 1960 ha in rabi\& 1960 in kharif.

\subsection{Dam characterstics}

The Bhaunrat Dam project has the following features

\begin{tabular}{|l|l|}
\hline LOCATION & \\
\hline Tehsil & No \\
\hline District & Lalitpur \\
\hline State & Uttar Pradesh \\
\hline River Basin & Betwa \\
\hline Nearest Railway Station & Lalitpur \\
\hline Nearest Airport & Gwalior/Bhopal \\
\hline Gross catchment area uptoDam Site & 335.40 Sq. km \\
\hline Free catchment area* & $358.90 \mathrm{Sq} . \mathrm{km}$ \\
\hline Average annual rainfall & $1018 \mathrm{~mm}$ \\
\hline Design flood for spillway & 5000 cumec \\
\hline DAM & \\
\hline Type & Homogeneous \\
\hline Max. height above river bed level & $19.93 \mathrm{~m}$ \\
\hline River bed level (above MSL) & $343.170 \mathrm{~m}$ \\
\hline Elevation of top of Dam & 363.1 \\
\hline Length of Dam Line & $4.20 \mathrm{Km}$ \\
\hline Length of Left Flank & $1.9715 \mathrm{Km}$ \\
\hline Length of Right Flank & $2.0715 \mathrm{Km}$ \\
\hline Width at top & $6.6 \mathrm{~m}$ \\
\hline Canals & Bhaunrat feeder channel $(2.5 \mathrm{~m} 3$ \\
\hline Freeboard & \\
\hline SPILLWAY & $2.2 \mathrm{~m}$ \\
\hline Type & \\
\hline Shape & ogee Spillway \\
\hline RESERVOIR and SUBMERGENCE & 354.550 \\
\hline Full Reservoir Level, FRL (above MSL) & \\
\hline Estimated Culturable Command Area (CCA) & 1230 ha of land \\
\hline No. of villages affected & 11699 hectares \\
\hline No. of families affected & 06 \\
\hline ESTIMATED COST & 1118 \\
\hline Civil Works & \\
\hline E and M Works & Rs. 388.52 Crore \\
\hline Total Basic Cost & Rs. 37 Crore \\
\hline CONSTRUCTION PERIOD & Rs. 423.45 Crore \\
\hline Target Year & $36 \mathrm{months}$ \\
\hline & \\
\hline
\end{tabular}




\section{Study Area of proposed project}

As per the EIA requirements, study area has been taken as $10 \mathrm{Kms}$ of from the dam line of the proposed Bhaunrat Dam site. Within the scope of study, the environmental parameters pertaining to water and air as per MoEF guidelines have been studied in the study area. The study area is shown Figure $1.2(\mathrm{a} \& \mathrm{~b})$. Photograph showing the site where proposed Bhaunrat dam shall be constructed are given in Figure 3.5. The D/s of Jamini River near the proposed dam site is given in Figure 3.6.

\section{Legend:}

ASL

WSL

VWSL

$$
\begin{aligned}
& \text { : air sampler location } \\
& \text { : water sample location } \\
& \text { : village water sample location }
\end{aligned}
$$

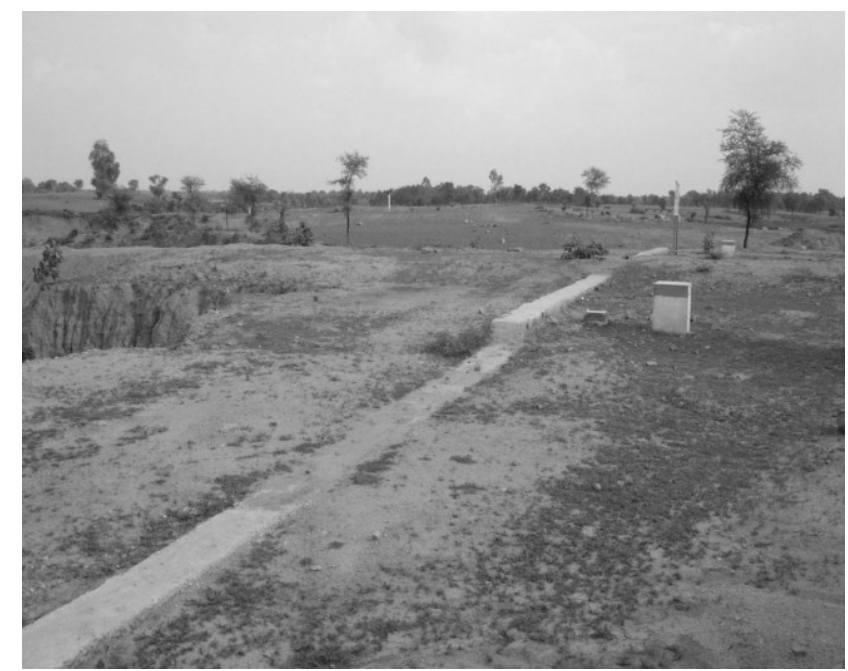

Fig 1.2: Proposed Site for Dam Construction

\section{Data Collection and its Analysis}

Within the scope of the study, parameters pertaining to water and air, relevant to dam projects have been investigated. These parameters have been investigated for three seasons (summer, Post-Monsoon and winter). The parameters are:

\section{Water Environment}

$\mathrm{pH}$

Alkalinity

Hardness

Turbidity

TDS

\section{Air Environment}

RSPM

SPM

For air sampling, random samples within 10 sq.km of project site has been conducted. Wind-rose analysis and diagram were beyond the scope of this study. There were practical constraints due to which windrose analysis could not be carried out. However, due to no industry in this area, air pollution is not an issue. 

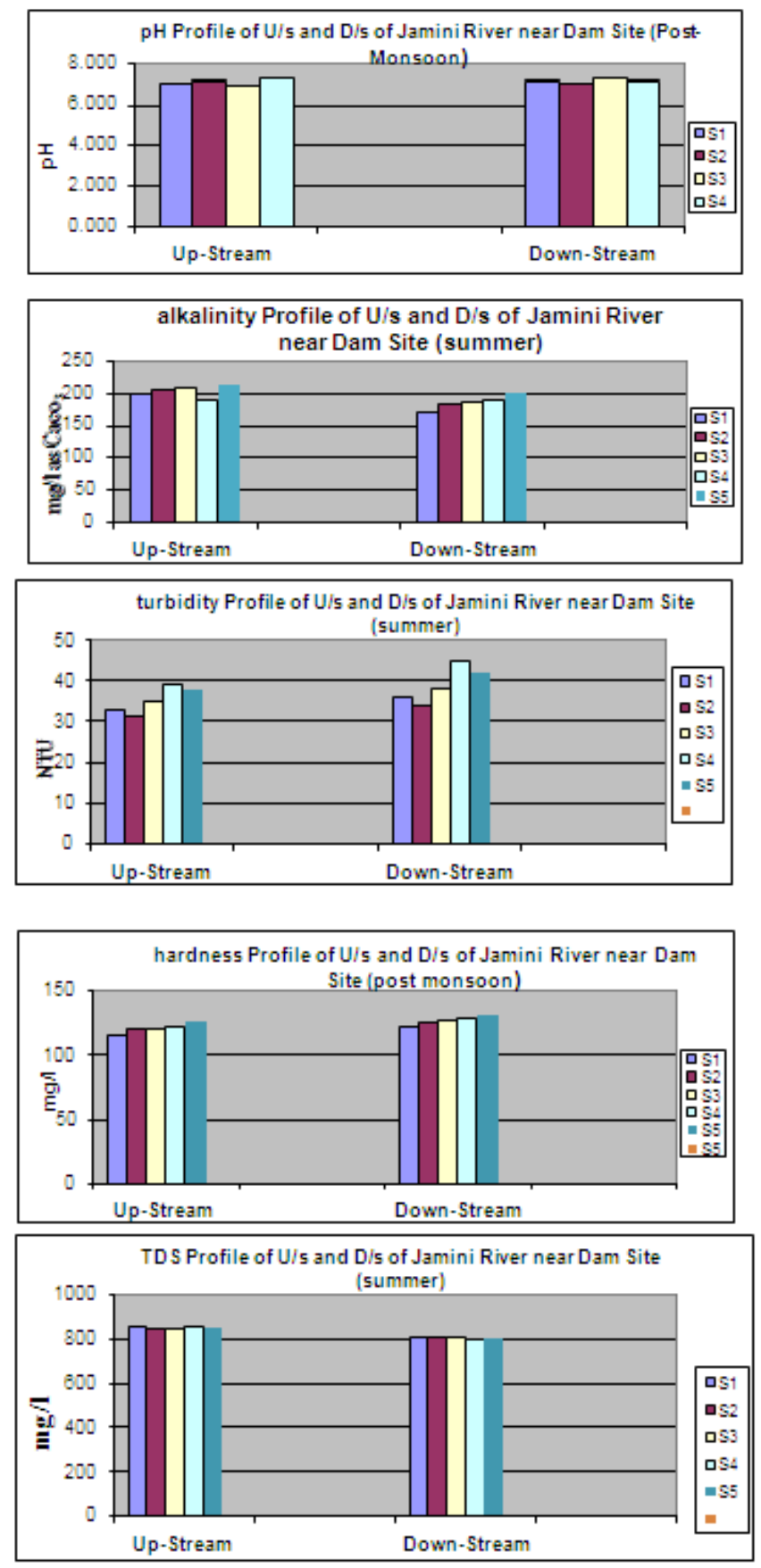

\section{Data of air sampling at Bhaunrat Dam site}

Table 1.1: Air Quality Monitoring Data at U/s of Bhaunrat Dam in Summr Season

\begin{tabular}{|c|c|c|}
\hline Location & RSPM $\left(\boldsymbol{\mu g} / \mathbf{m}^{\mathbf{3}}\right)$ & $\mathbf{S P M}\left(\boldsymbol{\mu g} / \mathbf{m}^{\mathbf{3}}\right)$ \\
\hline ASL1 & 71.27 & 52.32 \\
\hline ASL2 & 83.49 & 55.92 \\
\hline ASL3 & 81.26 & 54.26 \\
\hline ASL4 & 79.26 & 55.12 \\
\hline
\end{tabular}

Table 1.2: Air Quality Monitoring Data at U/s of Bhaunrat Dam in Post-Monsoon Season

\begin{tabular}{|c|c|c|}
\hline Location & RSPM $\left(\boldsymbol{\mu g} / \mathbf{m}^{\mathbf{3}}\right)$ & SPM $\left(\boldsymbol{\mu g} / \mathbf{m}^{\mathbf{3}}\right)$ \\
\hline ASL1 & 82.27 & 65.45 \\
\hline ASL2 & 81.94 & 59.35 \\
\hline ASL3 & 83.11 & 62.16 \\
\hline ASL4 & 81.11 & 61.31 \\
\hline
\end{tabular}




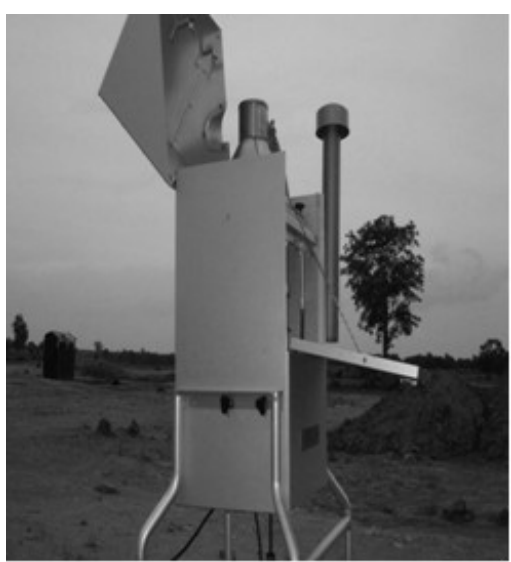

Figure 2.1: High Volume sampler installed at the proposed site

\section{Analysis of Results}

Parameters pertaining to water collected and analyzed in this study are $\mathrm{pH}$, Alkalinity, Turbidity, TDS, and Hardness.

The $\mathrm{pH}$ value of surface water (Jamini River) ranges in between 6 and $7(\mathrm{U} / \mathrm{s})$ and 6.3 and $7.0(\mathrm{D} / \mathrm{s})$. This indicates that there is hardly any variation in the $\mathrm{pH}$ during the flow of water of this river from upstream ( $5 \mathrm{kms}$ away from the dam line) to downstream ( $5 \mathrm{kms}$ away from the dam line). Thus, $\mathrm{pH}$ may not have significant role on the agriculture using this water.

In case of alkalinity, similar pattern have been obtained. The alkalinity concentration in the U/s of River ranges in between 200 and 225 whereas in $\mathrm{D} / \mathrm{s}$ it ranges from 155 to $200 \mathrm{mg} / \mathrm{l}$ as $\mathrm{CaCO}_{3}$. This shows that there is not much variation in these samples.

As for turbidity, results show 32 to 39 NTU in U/s of the river and 35 to 44 NTU in D/s of the River. This parameter may also not have any impact.

TDS and Hardness measured at the U/s and D/s of the river and ground water shows very little variation. TDS value ranges from 800 to $900 \mathrm{mg} / \mathrm{l}$ at U/s and D/s whereas hardness ranges from 115 to 225 at these two locations. This indicates that these parameter may not have any negative impact after the dam construction

\subsection{Results and discussion}

On the basis of the field surveys conducted and data collected, impact analysis has been carried out with respect to the environment with other features of the area/components.

1. Interaction Matrices Approach

2. Analysis of data on water, air and noise environment

\subsection{Environmental Impact}

On the basis of the field surveys conducted and data collected, net environmental impact has been carried out with respect to the Dam construction.

\begin{tabular}{|l|l|l|}
\hline \multicolumn{2}{|l|}{ Features likely to be affected } & Construction of dam \\
\hline Vegetation & forestry/vegetation & $-3 \mathrm{P}$ \\
\hline \multirow{4}{*}{ Wildlife } & Birds & $-1 \mathrm{~T}$ \\
\cline { 2 - 3 } & Fisheries & $-2 \mathrm{~T}$ \\
\cline { 2 - 3 } & other wildlife/animals & $-2 \mathrm{~T}$ \\
\hline \multirow{2}{*}{ Sedimentation } & sedimentation/erosion & $-2 \mathrm{P}$ \\
\hline \multirow{3}{*}{ Hydrology } & ground water recharge & $+3 \mathrm{P}$ \\
\cline { 2 - 3 } & Floods & $-1 \mathrm{P}$ \\
\hline \multirow{3}{*}{ Ecology } & land area & $-2 \mathrm{P}$ \\
\cline { 2 - 3 } & Climate & $\mathrm{Nil}$ \\
\hline \multirow{2}{*}{ Health } & drinking water & $+1 \mathrm{P}$ \\
\hline
\end{tabular}




\begin{tabular}{|l|l|l|}
\hline \multirow{5}{*}{} & water quality & $-1 \mathrm{~T}$ \\
\cline { 2 - 3 } & air quality & $-1 \mathrm{~T}$ \\
\cline { 2 - 3 } & health and safety & $-2 \mathrm{~T}$ \\
\hline & historical monuments & Nil \\
\cline { 2 - 3 } & Communication & $+2 \mathrm{P}$ \\
\hline \multirow{5}{*}{ Socio-economic } & Development & $+3 \mathrm{P}$ \\
\cline { 2 - 3 } & Agriculture & $+3 \mathrm{P}$ \\
\cline { 2 - 3 } & food production & $+1 \mathrm{P}$ \\
\cline { 2 - 3 } & public revenue income & $+2 \mathrm{~T}$ \\
\cline { 2 - 3 } & Industrialization & $+3 \mathrm{~T}$ \\
\cline { 2 - 3 } & Housing & $+1 \mathrm{P}$ \\
\hline & Employment & $+3 \mathrm{~T}$ \\
\hline & scenic views & $+1 \mathrm{~T}$ \\
\hline & Tourism & $+1 \mathrm{~T}$ \\
\hline
\end{tabular}

$\mathrm{T}=$ Temporary effect

$\mathrm{P}=$ Permanent effect

Designated scale

\begin{tabular}{|c|c|c|c|c|}
\hline & MILD & CONSIDERBLE & HIGH & VERY HIGH \\
\hline BENEFICIAL & +1 & +2 & +3 & +4 \\
\hline DETRIMENTAL EFFECTS & -1 & -2 & -3 & -4 \\
\hline
\end{tabular}

\subsection{Correlation with Inter-Disciplinary Components}

Following major aspects have been considered for correlation matrix

- Effect on Regional Ecology and Environment

- Dam construction

- Irrigation Benefits

- Forest Loss

- Regional Economy

- Social Aspects

- Geology

- Hydrology

These are the respective symbols use for different component
$\mathrm{S}=\quad$ Effect on Regional Ecology and Environment
$\mathrm{T}=$ Dam Construction
$\mathrm{U} \quad=\quad$ Irrigation Benefits
$\mathrm{V}=$ Forest Loss
$\mathrm{W}=\quad$ Regional Economy
$\mathrm{X}=$ Social Aspects
$\mathrm{Y} \quad=\quad$ Geology
$\mathrm{Z} \quad=\quad$ Hydrology

\begin{tabular}{|c|c|c|c|c|c|c|c|c|c|}
\hline \multirow[t]{2}{*}{ Compare } & \multicolumn{8}{|c|}{ With alternatives } & \multirow[t]{2}{*}{ SUM } \\
\hline & $\mathbf{S}$ & $T$ & $\mathbf{U}$ & $\mathbf{V}$ & $\mathbf{W}$ & $\mathbf{X}$ & $\mathbf{Y}$ & $\mathbf{Z}$ & \\
\hline $\mathbf{S}$ & - & 0.5 & 0.5 & 0 & 1 & 0.5 & 0 & 0 & 2.5 \\
\hline$T$ & 0.5 & - & 1 & 1 & 0.5 & 1 & 1 & 0.5 & 5.5 \\
\hline
\end{tabular}


Study of Water \& Air Environment for Impact Analysis of Proposed Bhaurant Dam .....

\begin{tabular}{|c|c|c|c|c|c|c|c|c|c|}
\hline $\mathbf{U}$ & 0.5 & 0 & - & 0 & 0.5 & 0 & 0.5 & 0.5 & 2.0 \\
\hline $\mathbf{V}$ & 1.0 & 0 & 1 & - & 0.5 & 0 & 0.5 & 0.5 & 2.0 \\
\hline $\mathbf{W}$ & 0 & 0.5 & 0.5 & 0.5 & - & 1 & 1 & 0 & 3.5 \\
\hline $\mathbf{X}$ & 0.5 & 0 & 1.0 & 1.0 & 0 & - & 0.5 & 0 & 3.0 \\
\hline $\mathbf{Y}$ & 1 & 0 & 0.5 & 0.5 & 0 & 0.5 & - & 0.5 & 3.0 \\
\hline $\mathbf{Z}$ & 1 & 0.5 & 0.5 & 0.5 & 0 & 0 & 0 & - & 2.5 \\
\hline
\end{tabular}

In this result all the five alternatives $\mathrm{S}, \mathrm{T}, \mathrm{U}, \mathrm{V}, \mathrm{W}, \mathrm{X}, \mathrm{Y}$, and $\mathrm{Z}$ are compared paired wise to each other. In this method First a matrix is drawn with all options listed both horizontally and vertically. Each option is then compared with every other one and a score of 1 assigned to the preferred option or 0.5 to both options if no preference zero is assigned.

On the basis of result it is found that sum of the preference of alternatives W (Dam construction) is three which is greater than other alternatives so conclusion of this result is that dam construction is more preferable option in that region rather than other components. This comparison shows that the dam construction is very beneficial with respect to all other parameters and it produces very less impact on environment that may be mitigated.

\section{Summary and conclusion}

On the basis of the study and analysis of data, the following conclusions are made:

1. Study has revealed that proposed dam at Bhaunrat dam, in District Lalitpur UP is more dominant over other aspects considered for correlation without causing any harm to the environment.

2. The proposed Bhaunrat Dam in District Lalitpur, which lies under semi-arid region, is a positive step by the state government as it would increase the Irrigation potential and Culturable Command Area (CCA) of this area.

3. Results pertaining to water and air analysis within the project area indicate that there will not be any adverse impact on ecology and environment following the construction of dam.

4. It is also concluded that the construction of dam shall increase the regional economy, green cover, and vegetation.

5. The dam will also act as a reservoir to recharge the ground water level of this region.

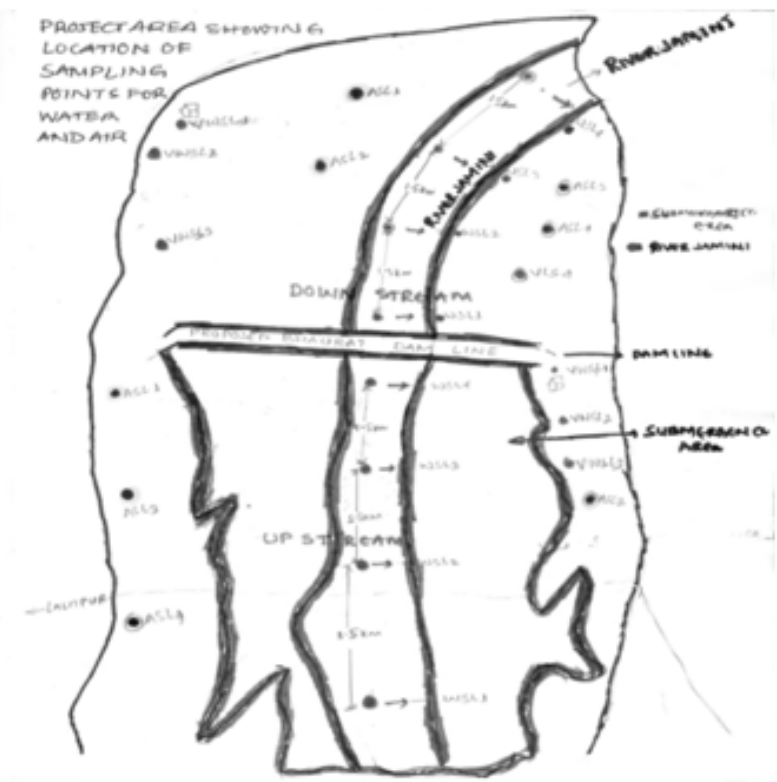

Fig: - Shows Study area and location of sample

\section{References}

[1]. Abu zeid and wagdy (1999), assessment of environmental impacts for irrigation project, decision support system

[2]. Alan Bond, Juan Palerm and Paul Haigh(2004) Environmental impact assessment and the decommissioning of nuclear power plants a review and suggestion for a best practicable approach.

[3]. Chantra Tongcumpou, Nick Harvey (2006) implications of recent eia changes in thailand 
[4]. Clark, B.D, Gilard, A, Bisset, R. and Tomlinson, R. (1984). perspectives on environmental impact assessment. Reidel publishing company, Holland.

[5]. Dubey, S, Newnes, D, (2003). Green democracy peoples participation in environmental decision making, environmental justice initiative.

[6]. Hugh Wilkins (2003) The need for subjectivity in EIA: discourse as a tool for sustainable development

[7]. James and jenifer, (2004) up streams channel following dam construction and removal using gis/remote sensing approach

[8]. Kohli, K, Menon, M, (2005). Eleven years of the environmental impact assessment notification, 1994, How effective has inbeen, kalpavrikswa environmental action group.

[9]. Matthew McCartney (2009) Living with dams: managing the environmental impacts;

[10]. NA. Siddiqui, R.N, Shukla and Akbar Ziauddin (2005) Environmental impact assessment (EIA) for a water resource project.

[11]. National Institute for Research in the Amazon, (2009) Environmental Impacts of Brazil's Tucuru1 Dam: Unlearned Lessons for Hydroelectric Development in Amazonia.

[12]. Ramesh Prasad Bhatt, Sanjay NathKhanal (2010) "Environmental impact assessment system and process: A study on policy and legal instruments in Nepal" African Journal of Environmental Science and Technology Vol. 4(9), pp. 586-594.

[13]. Sang-Yong Han a,, Seung-Jun Kwak b,1, Seung-HoonYoo c, Valuing environmental impacts of large dam construction in Korea: An application of choice experiments.

[14]. Sayadi, A. Khodadadi D., and S. Partani (2009) Environmental Impact Assessment of GotvandHydro-Electric Dam on the KaroonRiver UsingICOLD Technique ;Anna Brismar (2004)Attention to impact pathways in EISs of large dam projects;

[15]. The Hindu Survey of the environment, (2005) pg 91-97 Anjaneyulu, Y. Environment impact 